\title{
Expression and Diagnostic Value of Serum Protein Z, Protein Z-dependent Protease Inhibitor and Coagulation-related Indicators in Foetal Growth Restriction.
}

\author{
Xiaohua Luo ( $\nabla$ XiaoHuaLuo620@163.com ) \\ the third affiliated hospital of zhengzhou university \\ Yulian Huang \\ Tumor Hospital of Harbin Medical University \\ Cunhua Gu \\ the Third affiliated hospital of zhengzhou university \\ Xiaopei Guo \\ China-Japan Union Hospital of Jilin University \\ Jing Guo \\ China-Japan Union Hospital of Jilin University \\ Lingling Tao \\ the thrid affiliated hospital of zhengzhou university \\ Peiyan Sun \\ Shaanxi Provincial People's Hospital
}

Research article

Keywords: Foetal growth restriction, Protein Z, Protein Z-dependent protease inhibitor, Coagulation dysfunction, Diagnosis

Posted Date: August 13th, 2020

DOI: https://doi.org/10.21203/rs.3.rs-55936/v1

License: (c) (1) This work is licensed under a Creative Commons Attribution 4.0 International License. Read Full License 


\section{Abstract}

Objective. This study aimed to explore the expression and associations between levels of serum protein $Z$ (PZ), protein Z-dependent protease inhibitor (ZPI), and coagulation-related indicators and foetal growth restriction (FGR).

Methods. A total of 50 pregnant women with FGR, 50 healthy pregnant women (Healthy control, $\mathrm{HC}$ ), and 30 childbearing-age women without pregnancy group (Blank control, $B C$ ) were collected in this study. The serum PZ, ZPI, protein C (PC), protein C (PS), and antithrombin III (ATIII) levels of women in each group were determined and compared. Moreover, correlations between these indices and FGR were assessed using Spearman analysis and diagnostic values of these indices for FGR were evaluated using the receiver operating characteristics (ROC) curves.

Results. Serum levels of PZ, ZPI, PC, PS, and ATIII were significantly downregulated in the HC and FGR groups compared with the BC group $(P<0.001)$, while PZ, ZPI, PS, and ATIII levels in the FGR groups were significantly lower than that in the $\mathrm{HC}$ group $(P<0.01)$. PZ serum concentration was positively correlated with ZPI concentration in the $\mathrm{HC}$ and FGR groups, and PZ and ZPI levels were negatively correlated with FGR $(r=-0.198, r=-0.247, P<0.05)$. Combined of PZ, ZPI, PS, and ATIII performed a better value than each of them with AUC of $0.935(95 \% \mathrm{Cl}=0.890-0.981)$, a sensitivity of 0.920 , and a specificity of 0.800 .

Conclusion: Serum PZ, ZPI, PS, and ATIII were significantly decreased in pregnant women with FGR and could be used for FGR screening in pregnant women.

\section{Highlights}

1. PZ and ZPI expression in FGR women were significantly lower than that in normal pregnant women.

2. PS and ATIII expression in FGR women were significantly lower than that in normal pregnant women.

3. No significantly differences were identified in PZ, ZPI, PS, and ATIII between the second and third trimesters in FGR and normal pregnant women.

4. All PZ, ZPI, PS, and ATIII presented significantly diagnostic values for FGR screening.

5. Combined of PZ, ZPI, PS, and ATIII presented a promising diagnostic value than each of them for FGR screening.

\section{Background}

Foetal growth restriction (FGR) is traditionally defined as foetal growth less than the appropriate gestational age at 10 th percentile, which is leading cause for the morbidity and mortality of neonates ${ }^{[1]}$. Moreover, many of FGR survivors suffer lifelong changes in the risks of several diseases, such as neurodevelopment deficient, ischemic heart diseases, hypertension, diabetes, retinopathy, and other metabolic diseases ${ }^{[2-5]}$. Over the last decades, the FGR rate had markedly increased and likely to be Loading [MathJax]/jax/output/CommonHTML/jax.js 
factors exposure, including stress, nicotine, alcohol, and malnutrition ${ }^{[6,7]}$. Therefore, it is of significance to screen and intervene FGR as early to improve the perinatal outcome.

Till now, there are still no effective methods in identifying FGR among pregnancies due to the inappropriate medicalizations and biomarkers ${ }^{[8,9]}$. Thus, it is important to explore the etiology of FGR and identify some new candidates improving the diagnosis of FGR. In recent years, coagulation dysfunction is reported to reduce placental nutrient and oxygen exchange and might contribute to the development of FGR ${ }^{[10,11]}$. Histologic examination showed that fibrin deposition and thrombi in the vasculature were significantly increased in placentas of FGR pregnancies, including villous stem artery thrombosis, perivillous fibrin, and utero-placental and intervillous thrombi ${ }^{[12]}$. Torricelli et al. heve reported that protein $C$ (PC) and protein S (PS), two coagulation-related indicators, were significantly increased in preeclampsia (PE) and PE combined FGR groups compared with the control group [13]. In addition, another animal study showed that a coagulation-related indicator protein $C$ (PC) mRNA abnormally expressed in FGR rat model ${ }^{[14]}$. These findings suggested that coagulation dysfunction might be an important pathological characteristic of FGR, but how this characteristics could be use for FGR screening was still known.

Considering the coagulation disturbance during FGR, expression of coagulation related factors: PC, PS, and antithromnin (ATIII), and coagulation factor VII structure similar protein Z (PZ) and protein Zdependent protease inhibitor (ZPI) were determined among normal and FGR pregnant women followed by diagnostic value assessments. According to these investigation, we hope to provide some new insights and candidates for the screening of FGR.

\section{Methods}

\section{Subjects}

A total of 50 FGR pregnant women, who were hospitalized in the Department of Obstetrics, the Third Affiliated Hospital of Zhengzhou University, were enrolled in this study as the FGR group from Sept. 2018 to Sept. 2019. Patients enrolled in this group if they were: $\triangle$ all diagnosed with guideline of FGR authorized by the American College of Obstetricians and Gynecologists (ACOG) in 2019; $\otimes$ singleton under normal development; and $\nabla$ at least two indicators of abdominal circumference, femur length, biparietal diameter, foetal weight, and foetal head circumference diagnosed with ultrasonic less than 10th percentile of standard gestational age. In addition, participants were excluded if they met one of the following criteria during pregnancy: $\otimes$ smoking and/or alcoholism; $\otimes$ receiving antineoplastic agents, narcotic drugs or other pharmacotherapy that affect coagulation function; $₫$ combined with other pregnancy complications, including hypertensive disorders, diabetes mellitus, intrahepatic cholestasis, recurrent spontaneous abortion, and maternal-child blood group incompatibility; $\otimes$ diagnosed with

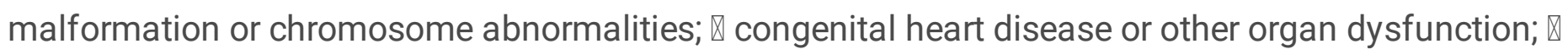




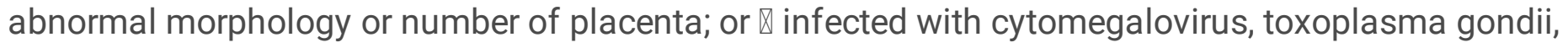
chickenpox, or syphilis.

Meanwhile, 50 cases of healthy pregnant women, who were received common examination and typical perinatal care, were enrolled in this study as the healthy control $(\mathrm{HC})$ group. Patients in this group were all met the following terms: $\otimes$ singleton with normal development; $\otimes$ last menstruation with a definite time

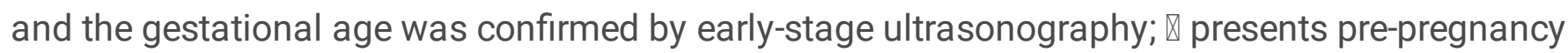
examination outcomes. Participants excluded criteria were the same as the FGR group.

In addition, 30 women at childbearing-age who were undergoing pre-pregnancy examination were selected as the black control (BC) group. Participants were enrolled if they were: $\otimes$ previously pregnant but not pregnant upon examination; and $₫$ presents adequate pre-pregnant examination results. However, participants would be excluded if they had: $\otimes$ smoking and drinking history; $₫$ history of drug exposure in

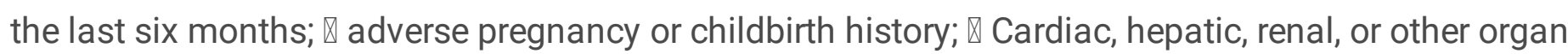
dysfunctions.

This study was authorized by the Ethics Committee of the Third Affiliated Hospital of Zhengzhou University (No.05). All subjects had signed the informed consent form before venous blood collection.

\section{Sample collection and preservation}

After enrollment, $2 \mathrm{ml}$ of fasting peripheral venous blood was collected from subjects using an EDTA vacuum anticoagulation tube and centrifuged at $4^{\circ} \mathrm{C}, 3500 \mathrm{r} / \mathrm{min}$ for $5 \mathrm{~min}$. Then, the supernatants were collected separately and stored at $-80^{\circ} \mathrm{C}$ for the following examinations.

\section{PZ and ZPI detection}

Levels of PZ and ZPI in serum were determined by double-antibody sandwich ELISA (Sino-American Biotechnology, Wuhan, China). Briefly, ten wells on the ELISA plate were used for the standard curve depiction according to the manufacturer's protocol. Then, blank wells (no sample or ELISA reagent) and test sample wells (the final sample dilution was 5 times) were respectively arranged, and $50 \mu$ of ELISA reagent was added to each well. After sealed, plate was incubated at $37^{\circ} \mathrm{C}$ for $30 \mathrm{~min}$. Then, the plate was uncovered, washed 5 times, and $50 \mu$ of developer A firstly added to each well followed by $50 \mu$ of developer B addition. Subsequently, colour development was carried out at dark for $10 \mathrm{~min}$, and the stop buffer was added to terminate the reaction. Within $15 \mathrm{~min}$, the absorbance (OD value) of each well was measured in sequence with the plate normalised against the blank well at $450 \mathrm{~nm}$. Taking the concentration of the standard as the ordinate and the OD value as the abscissa, the polynomial quadratic regression equation of the standard curve was calculated. The OD value of sample was substituted into the equation to calculate the concentration of the sample, which was then multiplied by the dilution, to get the actual concentration.

\section{PS, PC, and ATIII detection}


Plasma sample were taken out from $-80^{\circ} \mathrm{C}$ and thawed quickly. Then, PS was determined by the coagulation kit (Sino-American Biotechnology, Wuhan, China), and PC and ATIII were determined using the chromogenic substrate method (Sino-American Biotechnology, Wuhan, China). All tests were performed carefully according to the manufacturers' instructions.

\section{Statistical analyses}

Statistical analyses in the current study were performed using SPSS 21.0 software (SPSS Inc, Chicago, IL, USA). Specifically, homogeneity of variance and normality test were carried out from each group.

Normally distributed data were presented as mean \pm standard deviation $(\bar{x} \pm \mathrm{s})$ and abnormal distribution data were presented as median (percentile), namely, $\mathrm{M}\left(P_{25}, P_{75}\right)$. For normal distributed data, comparisons between groups were determined using the independent t-test and comparisons among groups were determined using a one-way ANOVA analysis followed by LSD test. For abnormal distribution data, comparisons between groups were estimated using nonparametric Mann-Whitney $U$ test and comparisons among groups were estimated using Kruskal-Wallis test. Correlation between PZ and ZPI concentrations was analyzed using the Pearson analysis and association between the concentrations of PZ and ZP1 and FGR were assessed using the Spearman rank analysis. Besides, the diagnostic value of each indicator or indicator combination was assessed using the receiver operating characteristics (ROC) curves. For all analyses, $P<0.05$ was considered statistically significant.

\section{Results}

\section{Generally information of enrolled subjects in three groups}

After enrollment, the general information of subjects, including age, gravidity, parity, gestational age, body mass index (BMI), were collected and compared. The results showed that there were no significant difference identified in the age $(P=0.23)$, gravidity $(P=0.068)$, parity $(P=0.18)$ among the $\mathrm{BC}, \mathrm{HC}$, and FGR groups (Table 1). In addition, no significant difference were identified in the gestational age $(P=$ $0.41)$ and $\mathrm{BMI}(P=0.77)$ between the HC and FGR groups. 
Table 1

Comparisons of general information of subjects among the BC, HC, and FGR groups

\begin{tabular}{|llllll|}
\hline Terms & BC & HC & FGR & $\chi^{2} / Z$ & $P$ \\
\hline Age (years) & $24(27.5,30)$ & $28(26,30)$ & $29(27.75,31)$ & 2.91 & 0.23 \\
\hline Gravidity & $1(1,2)$ & $2(1,3)$ & $2(1,3)$ & 5.37 & 0.068 \\
\hline Parity & $1(0,1)$ & $0(0,1)$ & $0.5(0,1)$ & 3.48 & 0.18 \\
\hline Gestational age & - & $28.16 \pm 3.78$ & $28.78 \pm 3.69$ & 0.83 & 0.41 \\
\hline BMI & - & $23.48 \pm 1.97$ & $23.61 \pm 2.32$ & 0.30 & 0.77 \\
\hline $\begin{array}{l}\text { Note: *: The gestational age was calculated based on the last menstruation and verified through early- } \\
\text { stage ultrasonography; \#: BMI, body mass index; BC, blank control, subjects in this group at } \\
\text { childbearing age without pregnancy; HC, healthy control, subjects in this group were normal } \\
\text { pregnancy; FGR, foetal growth restriction, subjects in this group were pregnancy with FGR. }\end{array}$ & \\
\hline
\end{tabular}

\section{Expression of PZ and ZPI among the BC, HC, and FGR groups}

To explore the variation of PZ and ZPI during pregnancy, the expression of PZ and ZPI were determined and compared among the $\mathrm{BC}, \mathrm{HC}$, and FGR groups. The results presented that the expression of $\mathrm{PZ}(P<$ $0.001)$ and ZP1 $(P<0.001)$ in serum were significantly differed among the $\mathrm{BC}, \mathrm{HC}$, and FGR groups (Table 2). Moreover, further inter-group analyses showed that the serum expression of PZ and ZP1 in the $\mathrm{HC}$ group were significantly higher than that in the $\mathrm{BC}$ group (all $\mathrm{P}<0.001$ ), but the serum expression of $P Z$ and $Z P I$ in the FGR group were significantly lower than that in the HC group (all $P<0.001$, Table 2 ), suggested that $\mathrm{PZ}$ and ZPI abnormal expression might involve in the pathogenesis of FGR. For further investigation, the expression of $\mathrm{PZ}$ and ZPI between the second and third pregnancy trimesters were also compared in the $\mathrm{HC}$ and FGR groups. However, no significantly differences were identified between the second and third pregnancy trimesters in the HC and FGR groups (all P > 0.05, Table 3). The data suggested that PZ and ZPI were significantly increased during pregnancy and abnormally decreased expression of PZ and ZPI in serum might be potential indicators for FGR during pregnancy. 
Table 2

Comparisons of serum PZ and ZPI among BC, HC, and FGR groups (|varvec $x \pm s$ )

\begin{tabular}{|c|c|c|c|}
\hline Terms & $\mathbf{n}$ & $\mathrm{PZ}(\mathrm{ng} / \mathrm{ml})$ & $\mathrm{ZPI}(\mathrm{ng} / \mathrm{ml})$ \\
\hline $\mathrm{BC} \otimes$ & 30 & $17.28 \pm 3.81$ & $6.50 \pm 1.21$ \\
\hline $\mathrm{HC} \otimes$ & 50 & $33.60 \pm 6.37$ & $13.33 \pm 2.39$ \\
\hline FGR $\otimes$ & 50 & $24.45 \pm 4.61$ & $9.74 \pm 1.87$ \\
\hline$F$ & & 97.202 & 116.827 \\
\hline$P$ & & $<0.001$ & $<0.001$ \\
\hline Inter-group $P$ : $\otimes$ vs. $\otimes$ & & $<0.001$ & $<0.001$ \\
\hline Inter-group $P$ : $\otimes$ vs. $\otimes$ & & $<0.001$ & $<0.001$ \\
\hline
\end{tabular}

Table 3

Comparisons of serum PZ and ZPI between the second and third trimesters ( $\mid$ varvec $X \pm \mathrm{s}$ )

\begin{tabular}{|lllll|}
\hline Terms & Trimester & $\mathbf{n}$ & $\mathbf{P Z}(\mathbf{n g} / \mathbf{m l})$ & ZPI (ng/ml) \\
\hline HC & Second & 24 & $33.77 \pm 6.49$ & $13.64 \pm 2.37$ \\
\cline { 2 - 4 } & Third & 26 & $33.44 \pm 6.38$ & $13.05 \pm 2.41$ \\
\hline$P$ & & 0.86 & 0.39 \\
\hline$t$ & & 0.182 & 0.88 \\
\hline FGR & Second & $23.92 \pm 4.92$ & $9.66 \pm 2.10$ \\
\cline { 2 - 4 } & Third & 31 & $28.79 \pm 16.53$ & $10.87 \pm 4.30$ \\
\hline$P$ & & 0.22 & 0.26 \\
\hline$t$ & & -1.25 & -1.14 \\
\hline $\begin{array}{l}\text { Note: PZ, protein Z; ZPI, protein Z-dependent protease inhibitor; HC, healthy control, subjects in this } \\
\text { group were normal pregnancy; FGR, foetal growth restriction, subjects in this group were pregnancy } \\
\text { with FGR. }\end{array}$ & \\
\hline
\end{tabular}

Considering the coagulation dysfunction in FGR, the expression of coagulation-related factors(PC, PS, and ATIII) were also determined among BC, HC, and FGR groups. As results, significant differences were Loading [MathJax]/jax/output/CommonHTML/jax.js 
identified in the expression of PC $(P=0.024), \mathrm{PS}(P<0.001)$, and ATIII $(P<0.001)$ among the BC, $\mathrm{HC}$, and FGR groups (Table 4). Moreover, further inter-group analyses showed that the expression of serum PC ( $P$ $<0.038)$ and $\mathrm{PS}(P<0.001)$ in the $\mathrm{HC}$ group were significantly lower than that in the $\mathrm{BC}$ group, but the expression of serum PS $(P<0.003)$ and ATIII $(P<0.001)$ were significantly higher than that in the FGR group and no markedly difference was identified in the expression of $\mathrm{PC}(P=0.47$, Table 4$)$. In addition, the expression levels of PC, PS, and ATIII between the second and third trimesters were also determined in the $\mathrm{HC}$ and FGR groups. However, no significant difference were identified in the expression levels of PC, PS, and ATIII between the second and third trimesters in the HC and FGR group (All P>0.05, Table 5). Taken together, these findings suggested that PS and ATIII expression levels were significantly decreased in FGR with a relative stable levels during pregnancy, which might could be used for FGR diagnosis.

Table 4

Comparisons of serum PC, PS, and ATIII among BC, HC, and FGR groups (|varvec $X \pm s$ )

\begin{tabular}{|c|c|c|c|c|}
\hline Terms & $n$ & $\mathrm{PC}(\%)$ & PS (\%) & ATIII (\%) \\
\hline $\mathrm{BC} \otimes$ & 30 & $118.86 \pm 14.19$ & $67.15 \pm 6.74$ & $100.84 \pm 11.79$ \\
\hline $\mathrm{HC} \otimes$ & 50 & $110.16 \pm 15.06$ & $44.88 \pm 8.01$ & $95.83 \pm 11.47$ \\
\hline FGR $\rrbracket$ & 50 & $107.58 \pm 18.47$ & $39.97 \pm 8.67$ & $86.80 \pm 11.42$ \\
\hline$F$ & & 3.83 & 77.94 & 15.32 \\
\hline$P$ & & 0.024 & $<0.001$ & $<0.001$ \\
\hline \multicolumn{5}{|c|}{ Inter-group $P$. } \\
\hline Qvs. $\nabla$ & & 0.038 & $<0.001$ & 0.085 \\
\hline Qvs. $\otimes$ & & 0.47 & 0.003 & $<0.001$ \\
\hline
\end{tabular}


Table 5

Comparisons of serum PC, PS, and ATIII between the second and third trimesters (|varvec $x \pm s$ )

\begin{tabular}{|llllll|}
\hline Terms & Trimester & $\mathbf{n}$ & $\mathbf{P C}(\%)$ & PS (\%) & ATIII (\%) \\
\hline HC & Second & 24 & $109.84 \pm 19.06$ & $46.12 \pm 8.17$ & $93.93 \pm 10.83$ \\
\cline { 2 - 6 } & Third & 26 & 110.4619 .50 & $43.74 \pm 7.84$ & $97.28 \pm 10.50$ \\
\hline$P$ & & 0.91 & 0.27 & 0.30 \\
\hline$t$ & & -0.11 & 1.05 & -1.11 \\
\hline FGR & Second & 24 & $103.21 \pm 20.747$ & $41.55 \pm 9.37$ & $89.62 \pm 8.77$ \\
\cline { 2 - 6 } & Third & 26 & $110.26 \pm 16.72$ & $36.01 \pm 8.22$ & $85.49 \pm 12.16$ \\
\hline$P$ & & 0.19 & 0.32 & 0.21 \\
\hline$t$ & & -1.32 & 1.01 & 1.29 \\
\hline $\begin{array}{l}\text { Note: PC, protein C; PS, protein S; ATIII, antithrombin; BC, blank control, subjects in this group at } \\
\text { childbearing age without pregnancy; HC, healthy control, subjects in this group were normal } \\
\text { pregnancy; FGR, foetal growth restriction, subjects in this group were pregnancy with FGR. }\end{array}$ \\
\hline
\end{tabular}

\section{Diagnostic value of PZ, ZPI, PS, and ATIII for FGR screening}

Pearson linear correlation analysis showed that the serum $\mathrm{PZ}$ concentration was positively correlated with ZPI concentration both in the HC group $(r=0.62, P<0.001$, Fig. 1A) and FGR group $(r=0.68, P<$ 0.001, Fig. 1B). Furthermore, associations between the serum levels of PZ and ZP1 and FGR were also assessed using the Spearman analysis. The results showed that PZ $(r=-0.198, P=0.024)$ and ZP1 $(r=$ $-0.25, P=0.005)$ were negatively correlated with FGR, respectively.

Considering of these findings, the diagnostic values of PZ, ZPI, and coagulation factors PS and ATIII for FGR screening were estimated using ROC curve. The results showed that all indices presented significantly diagnostic values and the diagnostic values in turn were: $\mathrm{PZ}(\mathrm{AUC}=0.878, P<0.001)>\mathrm{ZPI}$ $($ AUC $=0.87, P<0.001)>$ ATIII $($ AUC $=0.70, P=0.001)>$ PS $(A U C=0.64, P=0.015)($ Table 6 and Fig. $1 C)$. However, the specificities of PS and ATIII were only 0.36 and 0.56 , respectively. For further analysis, the combined diagnostic values of indices were also determined using ROC curves. The results showed that diagnostic sensitivities and specificities of combined indices were all more than 0.68 with all $P$ value $<$ 0.001 (Table 7 and Fig. 1D). Specifically, PZ + ZPI + PS + ATIII presented the highest diagnostic value with sensitivity of 0.92 , specificity of 0.80 , and AUC of $0.94(0.89-0.98)$. These evidences suggested that PZ, ZPI, PS, and ATIII could be used for FGR screening, and PZ + ZPI + PS + ATIII might be an optimal choice for FGR screening. 
Table 6

Diagnostic values of serum PZ, ZPI, PS, and ATIII for FGR assessed by ROC curves

\begin{tabular}{|llllll|}
\hline Terms & Specificity & Sensitivity & AUC $(95 \% \mathrm{Cl})$ & Cut-off & $P$ \\
\hline PZ & 0.72 & 0.86 & $0.88(0.81-0.94)$ & $29.50(\mathrm{ng} / \mathrm{ml})$ & 0.000 \\
\hline ZPI & 0.76 & 0.90 & $0.87(0.79-0.94$ & $11.92(\mathrm{ng} / \mathrm{ml})$ & 0.000 \\
\hline PS & 0.36 & 0.86 & $0.64(0.53-0.75)$ & $48.10(\%)$ & 0.015 \\
\hline ATIII & 0.56 & 0.82 & $0.70(0.59-0.80)$ & $96.55(\%)$ & 0.001 \\
\hline
\end{tabular}

Note: PS, protein S; ATIII, antithrombin; PZ, protein Z; ZPI, protein Z-dependent protease inhibitor.

Table 7

ROC curves of diagnostic value of combined serum PZ, ZPI, PS, and ATIII for FGR

\begin{tabular}{|lllll|}
\hline Terms & Sensitivity & Specificity & AUC $(95 \% \mathrm{Cl})$ & $P$ \\
\hline PZ + ZPI & 0.86 & 0.80 & $0.90(0.84-0.96)$ & $<0.001$ \\
\hline PS + ATIII & 0.72 & 0.68 & $0.75(0.66-0.85)$ & $<0.001$ \\
\hline PZ + ZPI + PS + ATIII & 0.92 & 0.80 & $0.94(0.89-0.98)$ & $<0.001$ \\
\hline Note: PS, protein S; ATIII, antithrombin; PZ, protein Z; ZPI, protein Z-dependent protease inhibitor. \\
\hline
\end{tabular}

\section{Discussion}

Placental insufficiency is widely accepted to be the primary cause of FGR, but the causes of placental insufficiency are various and complex ${ }^{[15]}$. Specifically, constricted spiral arteries and increased coagulation are contribute to fetal hypoxia and inappropriate nutrition exchange ${ }^{[16]}$. Hence, it is of important to explore the pathogenesis of coagulation dysfunction to improve the clinical diagnosis and therapy of FGR.

$\mathrm{PZ}$ is vitamin $\mathrm{K}$-dependent serum protein and commonly synthesized by vascular endothelial cells ${ }^{[17]}$. Its structure is similar to other K-dependent factors, such as VII, IX, and protein C ${ }^{[18]}$. Previous studies showed that $\mathrm{PZ}$ can acts an anticoagulant, like protein $\mathrm{C}$ and protein $\mathrm{S}$. ZPI is a member of serpin superfamily and could rapidly inhibit activation of factor Xa with the requirement of $\mathrm{PZ}$, calcium, and perocoagulant phospholipids, or suppress the activation of factor $\mathrm{XI}$ in the absence of the aforementioned cofactors ${ }^{[19]}$. Previous studies demonstrated that abnormal expression of serum PZ was related to adverse pregnancy outcomes, such as intrauterine foetal death, hypertensive disorders of pregnancy, recurrent spontaneous abortion, etc. ${ }^{[20-22]}$. Souri et al. had documented that serum PZ and ZPI levels in healthy pregnant women were significantly higher than that in the non-pregnant women ${ }^{\text {[23]. }}$ In this study, serum PZ and ZPI levels in the childbearing age without pregnant women (BC group) were also higher than that in the healthy pregnant women (HC group). Further explorations showed that serum Loading [MathJax]/jax/output/CommonHTML/jax.js , expression of ZPI in both HC and FGR groups. According to 
these evidences, we speculated that the hypercoagulable nature of pregnancy might be the possible reasons, which might lead to a compensatory increased synthesis of PZ and ZPI in the liver and inhibit the activation of $\mathrm{FXa}$, reducing the risk of thrombosis in pregnant women.

At present, the correlations between the expression of PZ and ZPI and FGR were still not elucidated. Quack et al. found that serum PZ level in normal pregnant women gradually increased with the increasing gestational age and returned to a normal level within three months after delivery ${ }^{[24]}$. Brettelle et al. had .demonstrated that nearly half of pregnant women with serum $\mathrm{PZ}$ deficiency had placental vascular abnormalities, and thus pointed out that the decrease in serum PZ level may be related to FGR ${ }^{\text {[21] }}$. However, Gowri et al. fount that no statistical significance was identified in the reduction of serum PZ level in pregnant women with FGR ${ }^{[25]}$. In this study, the serum PZ and ZPI levels were significantly downregulated in the FGR group compared with the normal pregnancy control, but no significant changes were identified in the second and third trimesters of pregnancy in both the normal pregnancy and FGR groups, indicating that insufficient serum PZ and ZPI levels may be a risk factor for FGR. In addition, further investigations showed that that serum concentrations of $\mathrm{PZ}$ and ZPI were negatively correlated with FGR. Considering of these findings, the diagnostic values of PZ and ZPI were determined with ROCs curve, and found that both PZ and ZPI presented higher diagnostic values. Combined these results, we speculated that deficiencies of PZ and ZPI might contribute to the development of FGR and could be utilized for the FGR screening in clinic.

Normal pregnancy is associated with a complicated of haematological variations, resulting in a hypercoagulable state ${ }^{[26]}$. PC, PS, and ATIII are three vitamin K-dependent anticoagulant proteins that are key roles in the coagulation regulation [27]. A previous study showed that PS was significantly decreased during pregnancy, ATIII was slightly decreased, but the PC expression was largely variated ${ }^{[28]}$. In the current study, significantly differences were identified in the expression of serum PC and PS, but not ATIII, between $\mathrm{BC}$ and $\mathrm{HC}$ women. These findings suggested that PS and ATIII might play key role during pregnancy, but the exact mechanism of them remains unknown.

A previous study showed that low levels of serum PS might be an increased risk for adverse outcomes at early pregnancy, including pre-eclampsia and hypertension, which might contribute to the development of FGR ${ }^{[29]}$. Besides, low expression of PC was also associated with the increased pregnancy loss ${ }^{[30]}$. Feotal thrombotic vascular has been emphasized recently in adverse pregnancy and low levels of PS, PC, and antithrombin were considered as risk factors for venous thromboembolism ${ }^{[31,32]}$. Previous studies had reported that deficiency of serum PS is associated with the development of FGR and acquired PS deficiency is mainly related to autoantibodies, which might enhance thrombosis, resulting in insufficient placental blood perfusion and development of FGR ${ }^{[33,34]}$. In this study, PS and ATIII were significantly decreased in FGR compared with the HC group, which provide direct evidence that PS and ATIII were play critical role in the pathogenesis of FGR. 
For further investigation, the expression of PC, PS, and ATIII in the second and third trimesters were also determined and showed no markedly changes between these two trimesters. Combined with PC expression variation between the $\mathrm{HC}$ and FGR, the diagnostic values of PS and ATIII were determined and both PS and ATIII presented significantly diagnostic values, but the specificity and sensitivity were not satisfied. Although PS combined ATIII presented a better diagnostic value than single of each, the diagnostic specificity was still less than 0.7 . Considering the diagnostic values of $\mathrm{PZ}$ and $\mathrm{ZPI}$, the diagnostic value of PZ, ZPI, PS, combined ATIII for FGR was assessed and presented a better than single index or two indices with an AUC of 0.935 , a sensitivity of 0.920 , and a specificity of 0.800 , indicating that combined use of the four had the highest clinical prediction value.

In conclusion, the reduction of serum PZ, ZPI, PS, and ATIII levels might associated with the coagulation dysfunction in pregnant women with FGR. With these expression changes, PZ, ZPI, PS, and ATIII were all presented significant diagnostic value for FGR and combined all of them showed the best diagnostic value for FGR screening. Therefore, it is of importance to detect the variations of PZ, ZPI, PS, and ATIII in pregnancy serum to improve the screening and therapy of FGR.

\section{Abbreviations}

Foetal growth restriction (FGR); Protein Z(PZ); Protein Z-dependent protease inhibitor(ZPI区;Healthy control(HC);Blank control(BC); protein C (PC);protein C (PS);antithrombin III (ATIII);receiver operating characteristics (ROC) ;preeclampsia (PE);black control (BC);American College of Obstetricians and Gynecologists (ACOG);body mass index (BMI).

\section{Declarations}

\section{Ethics approval and consent to participate】}

All women signed the informed consent form before collection of venous blood. The collection and use of samples for study purposes was approved by the hospital's Ethics Committee,The number is 2019 hospital ethics committee review no.05.

\section{Consent for publication:}

All the women's basic information obtained their consent and signed an informed consent form.

\section{Competing interests:}

The authors declare no competing interests. 
Funding from the Joint Construction Project of Henan Programs for Medical Science and Technology Development is gratefully acknowledged.

\section{Authors' contributions】}

(1) Concept and design: Xiao-Hua Luo;

(2)Provision of study materials and patiens:Yu-Lian Huang ;

(3)Collection and assembly of data: Xiao-Pei Guo,Cun-Hua Gu and Jing Guo;

(4)Data analysis and interpretation: Yu-Lian Huang, Ling-Ling Tao and Pei-Yan Sun;

(5)Manuscript writing:all authors;

(6)Final approval of manuscript: all authors.

The authors are accountable for all aspects of the work in ensuring that questions related to the accuracy or integrity of any part of the study are appropriately investigated and resolved.

\section{Acknowledgements】}

Supported by Joint Construction Project of Henan Programs for Medical Science and Technology Development (2018020175).

\section{References}

1. Børte S, Winsvold BS, Stensland S, Småstuen MC, Zwart J-A. The effect of foetal growth restriction on the development of migraine and tension-type headache in adulthood. The HUNT Study. PLOS ONE. 2017;12(4):e0175908.

2. Lappas M, McCracken S, McKelvey K, Lim R, James J, Roberts CT, et al. Formyl peptide receptor-2 is decreased in foetal growth restriction and contributes to placental dysfunction. Mol Hum Reprod. 2017;24(2):94-109.

3. Healy P, Gordijn S, Ganzevoort W, Beune I, Baschat A, Khalil A, et al. Core Outcome Set for GROwth restriction: deVeloping Endpoints (COSGROVE). Trials. 2018;19(1):451.

4. Cohen E, Whatley C, Wong FY, Wallace EM, Mockler JC, Odoi A, et al. Effects of foetal growth restriction and preterm birth on cardiac morphology and function during infancy. Acta Paediatr. 2018;107(3):450-5. 
5. Baud O, Berkane N. Hormonal changes associated with intra-uterine growth restriction: impact on the developing brain and future neurodevelopment. Frontiers in Endocrinology. 2019;10:179.

6. Colella M, Frérot A, Novais AR, Baud O. Neonatal and long-term consequences of fetal growth restriction. Current pediatric reviews. 2018;14(4):212-8.

7. Chabrun F, Huetz N, Dieu X, Rousseau G, Bouzillé G, Chao de la Barca JM, et al. Data-Mining Approach on Transcriptomics and Methylomics Placental Analysis Highlights Genes in Fetal Growth Restriction. Frontiers in Genetics 2020; 10(1292).

8. Smith GC. Universal screening for foetal growth restriction. Best practice research Clinical obstetrics gynaecology. 2018;49:16-28.

9. Augusthy VC. Fetal growth restriction: aetiology, screening, diagnosis and management. Int J Reprod Contracept Obstet Gynecol. 2015;4(6):1672-7.

10. Kraus FT. Fetal Thrombotic Vasculopathy: Perinatal Stroke, Growth Restriction, and Other Sequelae. Surgical Pathology Clinics. 2013;6(1):87-100.

11. D'Asti E, Kool M, Pfister SM, Rak J. Coagulation and angiogenic gene expression profiles are defined by molecular subgroups of medulloblastoma: evidence for growth factor-thrombin cross-talk. $J$ Thromb Haemost. 2014;12(11):1838-49.

12. Chui A, Zainuddin N, Rajaraman G, Murthi P, Brennecke SP, Ignjatovic V, et al. Placental Syndecan Expression Is Altered in Human Idiopathic Fetal Growth Restriction. Am J Pathol. 2012;180(2):693702.

13. Torricelli M, Sabatini L, Florio P, Scaccia V, Voltolini C, Biliotti G, et al. Levels of antibodies against protein $\mathrm{C}$ and protein $\mathrm{S}$ in pregnancy and in preeclampsia. The Journal of Maternal-Fetal Neonatal Medicine. 2009;22(11):993-9.

14. Buffat C, Boubred F, Mondon Fo, Chelbi ST, Feuerstein J-M, Lelièvre-Pégorier M, et al. Kidney Gene Expression Analysis in a Rat Model of Intrauterine Growth Restriction Reveals Massive Alterations of Coagulation Genes. Endocrinology. 2007;148(11):5549-57.

15. Fleiss B, Wong F, Brownfoot F, Shearer IK, Baud O, Walker DW, et al. Knowledge gaps and emerging research areas in intrauterine growth restriction-associated brain injury. Front Endocrinol. 2019;10:188.

16. Ndour D, Gassama O. Intrauterine Growth Retardation, Fetal Growth Restriction: Impact on Brain Development. EC Paediatrics. 2019;8:810-9.

17. Vasse M, Denoyelle C, Corbière C, Litzler P-Y, Legrand E, Vannier J-P. Human endothelial cells synthesize protein Z, but not the protein Z dependent inhibitor. Thromb Haemost. 2006;95(03):51923.

18. Szumowska A, Galar M, Bolkun L, Kloczko J. Plasma Concentrations of Protein Z and Protein ZDependent Protease Inhibitor in Patients With Essential Thrombocythemia. Clin Appl Thromb Hemost. 2016;22(7):679-84.

19. Huang X. Engineering a protein Z-dependent protease inhibitor (ZPI) mutant as a novel antagonist of Loading [MathJax]/jax/output/CommonHTML/jax.js lia treatment. J Thromb Haemost. 2019;17(10):1655-60. 
20. Al-Shaikh FS, Sater MS, Finan RR, Racoubian E, Abu-Hijleh TM, Mustafa FE, et al. Protein Z variants associated with protein $Z$ plasma levels and with risk of idiopathic recurrent miscarriage. Reproductive Sciences. 2013;20(9):1062-8.

21. Bretelle F, Arnoux D, Shojai R, D'Ercole C, Sampol J, Dignat F, et al. Protein Z in patients with pregnancy complications. American journal of obstetrics gynecology. 2005;193(5):1698-702.

22. Erez O, Hoppensteadt D, Romero R, Espinoza J, Goncalves L, Nien JK, et al. Preeclampsia is associated with low concentrations of protein Z. The Journal of Maternal-Fetal Neonatal Medicine. 2007;20(9):661-7.

23. Souri M, Sugiura-Ogasawara M, Saito S, Kemkes-Matthes B, Meijers JC, Ichinose A. Increase in the plasma levels of protein Z-dependent protease inhibitor in normal pregnancies but not in nonpregnant patients with unexplained recurrent miscarriage. Thromb Haemost. 2012;107(03):507-12.

24. Loetscher KCQ, Stiller R, Roos M, Zimmermann R. Protein Z in normal pregnancy. Thromb Haemost. 2005;93(04):706-9.

25. Gowri V, Mathew M, Gravell D, AlFalahi K, Zakwani I, Ganguly SS, et al. Protein Z levels in pregnant Omani women: correlation with pregnancy outcome. J Thromb Thrombolysis. 2011;32(4):453.

26. Ho VT, Dua A, Lavingia K, Rothenberg K, Rao C, Desai SS. Thrombolysis for Venous Thromboembolism During Pregnancy: A Literature Review. Vascular Endovascular Surgery. 2018;52(7):527-34.

27. Mekaj Y, Lulaj S, Daci F, Rafuna N, Miftari E, Hoxha H, et al. Prevalence and role of antithrombin III, protein $\mathrm{C}$ and protein $\mathrm{S}$ deficiencies and activated protein $\mathrm{C}$ resistance in Kosovo women with recurrent pregnancy loss during the first trimester of pregnancy. Journal of human reproductive sciences. 2015;8(4):224.

28. Kristoffersen AH, Petersen PH, Røraas T, Sandberg S. Estimates of Within-Subject Biological Variation of Protein C, Antithrombin, Protein S, Free PS Activity, and Activated Protein C Resistance in Pregnant Women. Clinical Chemistry 2017; 63(4):898-907.

29. Ebina Y, leko M, Naito S, Kobashi G, Deguchi M, Minakami H, et al. Low levels of plasma protein S, protein $\mathrm{C}$ and coagulation factor XII during early pregnancy and adverse pregnancy outcome. Thromb Haemost. 2015;114(07):65-9.

30. Igwe CA, Charles AT, Mgbeoma EE, Ogechi NE. Assessment of Protein C and Protein S of Pregnancy Loss Victims. International Blood Research \& Reviews 2019:1-7.

31. Bucciarelli P, Passamonti S, Biguzzi E, Gianniello F, Franchi F, Mannucci P, et al. Low borderline plasma levels of antithrombin, protein $\mathrm{C}$ and protein $\mathrm{S}$ are risk factors for venous thromboembolism. J Thromb Haemost. 2012;10(9):1783-91.

32. Calzavarini S, Prince-Eladnani R, Saller F, Bologna L, Burnier L, Brisset AC, et al. Platelet protein S limits venous but not arterial thrombosis propensity by controlling coagulation in the thrombus. Blood The Journal of the American Society of Hematology. 2020;135(22):1969-82.

33. De Bonis M, Sabatini L, Galeazzi LR, Torricelli M, Calzoni P, Fineschi D, et al. Maternal serum protein S Loading [MathJax]/jax/output/CommonHTML/jax.js trauterine growth restriction. European Journal of Obstetrics 
Gynecology Reproductive Biology. 2012;160(2):142-6.

34. Dłuski D, Mierzyński R, Poniedziałek-Czajkowska E, Leszczyńska-Gorzelak B. Adverse pregnancy outcomes and inherited thrombophilia. Journal of perinatal medicine. 2018;46(4):411-7.

Figures

A

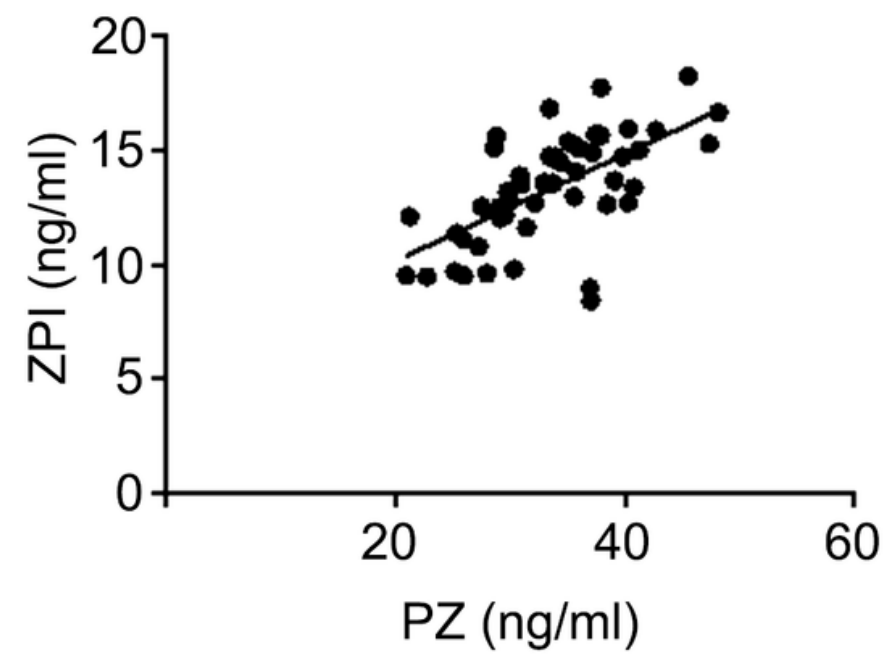

C

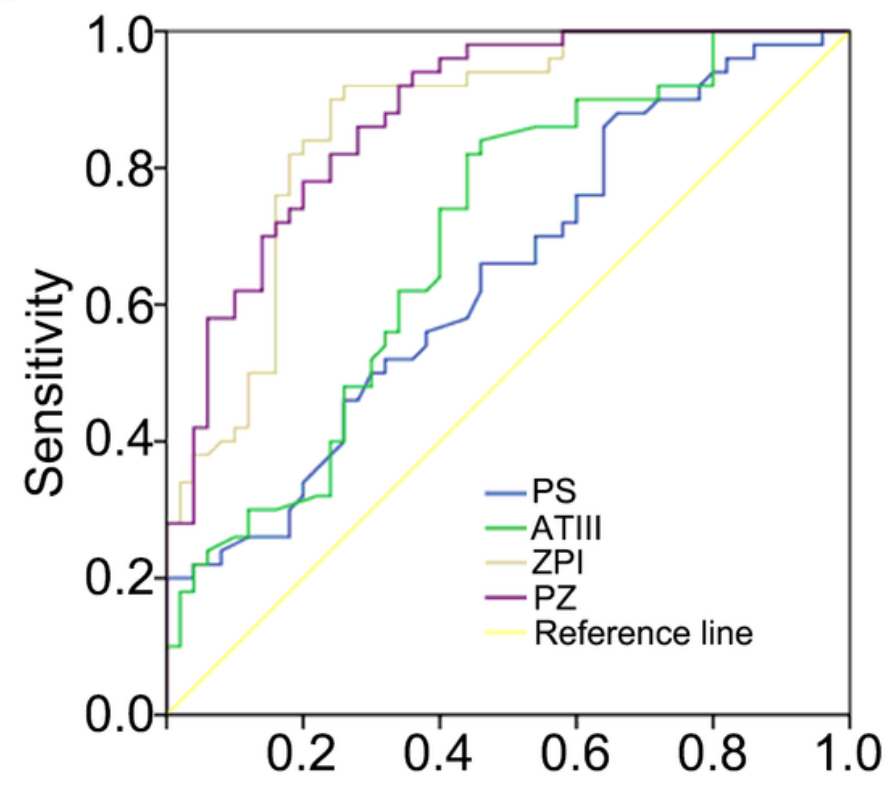

B

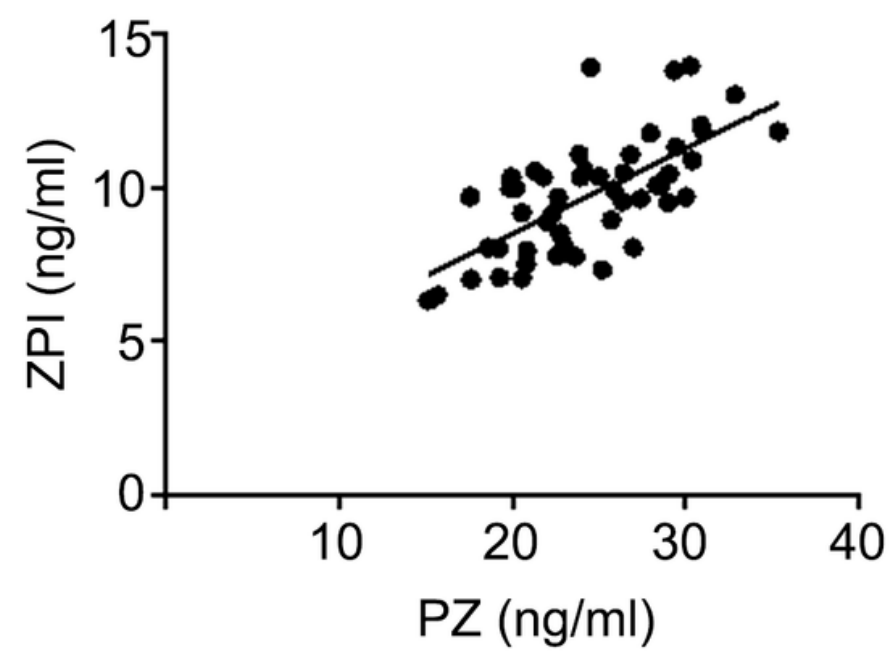

$\mathrm{D}$

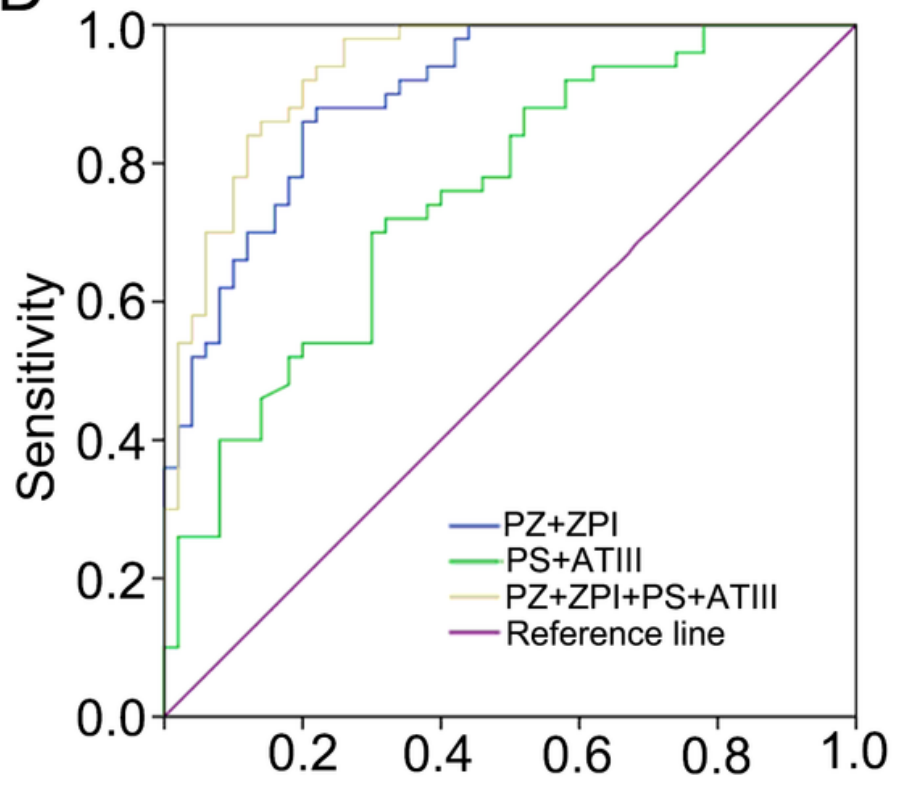

Figure 1

Diagnostic value of PZ, ZPI, PS, and ATIII for FGR A, correlations between PZ and ZPI in normal pregnant women: B. correlations between PZ and ZPI in FGR; C, Diagnostic value of PZ, ZPI, PS, or ATIII assessed Loading [MathJax]/jax/output/CommonHTML/jax.js 
using ROC curve; D, Diagnostic values of combined indices of PZ, ZPI, PS, or ATIII assessed using ROC curve. PZ, protein Z; ZPI, protein Z-dependent protease inhibitor; PC, protein C; PS, protein S; ATIII, antithromnin; FGR, foetal restriction growth.

Loading [MathJax]/jax/output/CommonHTML/jax.js 